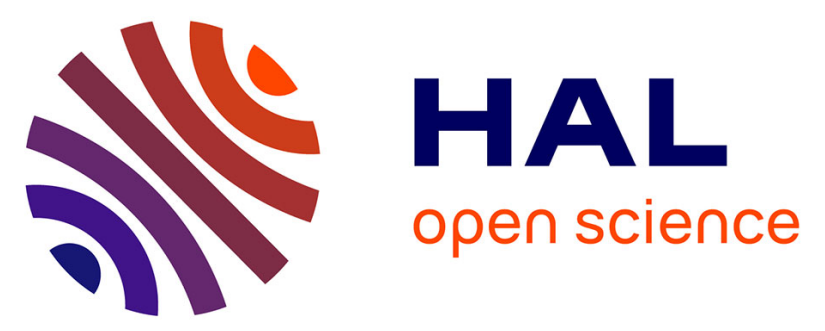

\title{
Double-duty solutions for optimising maternal and child nutrition in urban South Africa: a qualitative study
} Agnès Erzse, Suzanne Goldstein, Shane A Norris, D. Watson, Sarah Kehoe, Mary Barker, Emmanuel Cohen, Karen J Hofman

\section{- To cite this version:}

Agnès Erzse, Suzanne Goldstein, Shane A Norris, D. Watson, Sarah Kehoe, et al.. Double-duty solutions for optimising maternal and child nutrition in urban South Africa: a qualitative study. Public Health Nutrition, 2021, 24 (12), pp.3674-3684. 10.1017/S1368980020002426 . hal-03251775

\section{HAL Id: hal-03251775 \\ https://hal.science/hal-03251775}

Submitted on 30 Nov 2021

HAL is a multi-disciplinary open access archive for the deposit and dissemination of scientific research documents, whether they are published or not. The documents may come from teaching and research institutions in France or abroad, or from public or private research centers.
L'archive ouverte pluridisciplinaire HAL, est destinée au dépôt et à la diffusion de documents scientifiques de niveau recherche, publiés ou non, émanant des établissements d'enseignement et de recherche français ou étrangers, des laboratoires publics ou privés. 


\title{
Double-duty solutions for optimising maternal and child nutrition in urban South Africa: a qualitative study
}

\author{
Agnes Erzse ${ }^{1, *}$, Susan Goldstein ${ }^{1}$, Shane A Norris ${ }^{2,3}$, Daniella Watson ${ }^{3}$ (1), \\ Sarah H Kehoe ${ }^{4}$, Mary Barker ${ }^{4}$, Emmanuel Cohen ${ }^{2,5}$ and Karen J Hofman ${ }^{1}$ \\ 'SAMRC/Centre for Health Economics and Decision Science, PRICELESS SA, School of Public Health, Faculty of Health \\ Sciences, University of the Witwatersrand, Johannesburg, South Africa: ${ }^{2}$ SAMRC/Wits Developmental Pathways for \\ Health Research Unit (DPHRU), School of Clinical Medicine, Faculty of Health Sciences, University of the \\ Witwatersrand, Johannesburg, South Africa: ${ }^{3}$ School of Human Development and Health, Faculty of Medicine, \\ University of Southampton, Southampton, UK: ${ }^{4}$ MRC Lifecourse Epidemiology Unit, University of Southampton and \\ NIHR Southampton Biomedical Research Centre, University Hospitals Southampton NHS Foundation Trust, \\ Southampton, UK: ${ }^{5}$ Musée de l'Homme, Muséum National d'Histoire Naturelle, UMR-CNRS 7206 Eco-anthropology, \\ Paris, France
}

Submitted 3 December 2019: Final revision received 2 June 2020: Accepted 22 June 2020: First published online 24 August 2020

\begin{abstract}
Objective: To obtain a community perspective on key nutrition-specific problems and solutions for mothers and children.

Design: A qualitative study comprising nine focus group discussions (FGD) following a semi-structured interview guide.

Setting: The township of Soweto in South Africa with a rising prevalence of double burden of malnutrition.

Participants: Men and women aged $\geq 18$ years ( $n$ 66). Three FGD held with men, six with women.

Results: Despite participants perceived healthy diet to be important, they felt their ability to maintain a healthy diet was limited. Inexpensive, unhealthy food was easier to access in Soweto than healthier alternatives. Factors such as land use, hygiene and low income played a fundamental role in shaping access to foods and decisions about what to eat. Participants suggested four broad areas for change: health sector, social protection, the food system and food environment. Their solutions ranged from improved nutrition education for women at clinic visits, communal vegetable gardens and government provision of food parcels to regulatory measures to improve the healthiness of their food environment.

Conclusions: South Africa's current nutrition policy environment does not adequately address community-level needs that are often linked to structural factors beyond the health sector. Our findings suggest that to successfully address the double burden of malnutrition among women and children, a multifaceted approach is needed combining action on the ground with coherent policies that address upstream factors, including poverty. Further, there is a need for public engagement and integration of community perspectives and priorities in developing and implementing double-duty actions to improve nutrition.
\end{abstract}

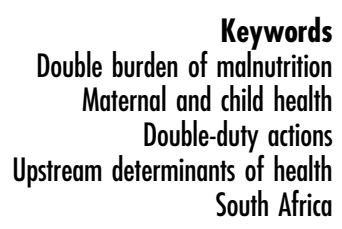

South Africa, a middle-income country, is undergoing a socioeconomic transition that has triggered a rapid change in dietary habits towards consumption of less nutritious, more processed food, high in sugar, fat, salt and low in fibre $^{(1,2)}$. This dietary shift results in a double burden of malnutrition - the coexistence of under and over nutrition - that manifests both at the population and individual levels ${ }^{(3,4)}$. At the population level, a national study found that in 2016, $13 \%$ of children under 5 years were overweight or obese, while the prevalence of stunting was $27 \%{ }^{(5)}$. Studies conducted in communities in a rural health and demographic surveillance site showed the coexistence of early stunting and adolescent overweight/ obesity followed by an elevated risk for metabolic disease in adolescent girls $^{(6)}$, and high overweight/obesity rates among women of reproductive age ${ }^{(7)}$. In individuals, the 
co-prevalence of stunting and overweight in 3-year-old children was an estimated $19 \%{ }^{(4)}$. This combination of under and over nutrition has adverse effects throughout the life course, and has been described as a leading cause of death, disability and ill-health globally ${ }^{(8)}$. Optimising the nutritional status of children and their mothers prior to and during pregnancy improves growth and cognitive development in children and potentially reduces their risk for non-communicable diseases (NCD) in later life $\mathrm{e}^{(9,10)}$

The imperative for action on all forms of malnutrition is reflected in South Africa's NCD strategic plan ${ }^{(11)}$, the National Development Plan 2030(12) and in the 2030 Agenda for Sustainable Development, particularly Goal $2^{(13)}$. The solutions are, however, less well articulated than the problem. In 2017, the WHO called for a greater prioritisation of 'double-duty' interventions that target common drivers of both under nutrition and overweight $^{(14)}$. Most of these policies are top-down, but will need to be culturally appropriate and context-relevant for successful implementation in South Africa. There is little knowledge of how nutritional issues are understood by South African communities or how they perceive solutions to these problems. Without seeking these views, we cannot fully understand the operation of these common drivers of under and over nutrition.

This qualitative research was designed to learn from the lived experiences of men and women in Soweto to identify issues that they perceived to be important in shaping maternal and child nutrition, and to obtain their suggestions for solutions to these problems. This is a novel approach to policy formulation in South Africa where community perspectives are underutilised in the design and implementation of nutrition interventions and policies.

This is a sub-study of a larger NIHR-funded international collaboration, 'Improved Nutrition Preconception Pregnancy Post-Delivery (INPreP)'. The INPreP partners are based in Burkina Faso, Ghana, South Africa and the UK (www.inprep.soton.ac.uk). Findings from qualitative sub-studies (Compaoré et al., 2020 (15), Debpuur et al., $2020^{(16)}$, Watson et al., 2020 (17)) are vital to achieving INPreP's aim of developing supportive nutrition interventions in the 'first $1000 \mathrm{~d}$ plus' (preconception, pregnancy and first 2 years) period to simultaneously reduce the risk and burden of under and over nutrition in this population.

\section{Methods}

\section{Study setting and population}

The current study was conducted in Soweto, Johannesburg, South Africa, a rapidly transitioning urban setting with a significant and rising prevalence of double burden of malnutrition. The prevalence of stunting in this setting among 2 -year-old children is $>34 \%{ }^{(18)}$ compared with a national average of $27 \%$. In the same population, the prevalence of overweight and obesity ranges from 19 to $36 \%$ among black women between the age of 12 and 19, compared with a range of $22-26 \%$ among their white peers ${ }^{(18)}$. Women in Soweto are at a particular risk, with clustering of nutrition-related conditions including $66 \%$ overweight and obesity, 9.1\% gestational diabetes mellitus and $31 \%$ anaemia $^{(19-21)}$.

\section{Data collection}

A qualitative approach was chosen to explore community opinions, values and key concerns about maternal and child nutrition. Focus group discussions (FGD) were selected as the most appropriate method that allowed the collection of a variety of perceptions on the research topic, arising from an interaction between participants ${ }^{(22)}$. Study participants were purposively selected from the Chris Hani Baragwanath Hospital minibus Taxi Rank in Soweto, which is the main road transport hub for about $70 \%$ of Sowetans ${ }^{(23)}$. Participants included men and women aged $\geq 18$ years. Women's FGD were held in three age groups to cover the different stages of the reproductive life course and to potentially avoid older women inhibiting younger women's (18-25, 26-40 and $>40$ years) expressions.

A common semi-structured discussion guide was developed for all three sites (Soweto in South Africa, Nanoro in Burkina Faso and Navrongo in Ghana) to enable comparisons of findings between sites. Thereafter, the guide was adapted for the Soweto context. FGD took place at a research centre within the Chris Hani Baragwanath Hospital complex, of close proximity to the taxi rank, in a private room to avoid disturbance and to create a comfortable atmosphere for participants. Participants were reimbursed for transport costs on the day of FGD.

FGD were facilitated by two multilingual fieldworkers trained by the researchers (AE, SG, EC) prior to data collection. Fieldworkers read out the information sheet to participants who then provided written consent for both participating and audio-recording the interview. FGD were conducted in the vernacular language (Xhosa, Zulu or English), audio-recorded, transcribed and translated into English where necessary. Discussions were held on weekdays, during working hours between 09.00 and 16.00 and lasted approximately an hour. After the ninth focus group, no more new data were generated from the discussion with community members. Transcripts were then checked for accuracy by the lead author (AE). Observational notes were produced during the FGD by fieldworkers. Data were also collected on participants' sociodemographic characteristics, including gravidity, parity, marital status, number of people in the household and socioeconomic status (SES) prior to the discussion. 


\section{Data analysis}

Focus group transcripts were read multiple times by two researchers (AE, SG) to achieve immersion in the content and flow of the discussion. Thereafter, transcripts were coded using NVivo (version 12) ${ }^{(24)}$. Deductive codes were based on key domains relating to the interview questions, such as 'key health issues', 'key nutrition issues', 'current nutrition services' and 'recommended nutrition services'. Domain summaries were used in the identification of themes through a reflexive thematic analysis ${ }^{(25)}$. Through the analysis, researchers developed an understanding of recurring themes across the dataset, simultaneously reflecting on the answers. Reporting of findings adheres to COREQ guidelines ${ }^{(26)}$.

\section{Results}

\section{Participant characteristics}

Twenty-one men participated in three FGD, and 45 women took part in another six FGD (Table 1). Participant characteristics are presented in Table 2. Most participants were of low SES, with household incomes <ZAR 5000 (345 USD) per month. About half of respondents had completed high school (locally referred to as 'matric') or had completed further education; this proportion is comparable with other Sowetan men and women of the same age ${ }^{(27)}$.

\section{Findings from the focus group discussions}

Results are presented thematically, and data are reported in alignment with four themes that emerged from the analysis: (1) awareness of optimal nutrition, (2) barriers to optimal nutrition in the physical environment, (3) healthy diet constrained by socioeconomic hardship, (4) optimising nutrition in desperate conditions. Under each theme, results are supported by illustrative quotes.

\section{Awareness of optimal nutrition}

Discussions revolved around the importance of 'healthy food' and the avoidance of 'unhealthy food'. Participants' ideas of healthy foods included fruits, vegetables, water and milk. When referred to unhealthy food, they mentioned food cooked with too much oil and salt, street

Table 1 Details of participants in focus group discussions (FGD)

\begin{tabular}{lccl}
\hline FGD no. & Participants $(n)$ & Age group & Gender \\
\hline 1 & 11 & $26-40$ & Women \\
2 & 7 & $26-40$ & Women \\
3 & 6 & $18-25$ & Women \\
4 & 7 & $18-25$ & Women \\
5 & 7 & $18+$ & Men \\
6 & 6 & $40+$ & Women \\
7 & 8 & $18+$ & Men \\
8 & 8 & $40+$ & Women \\
9 & 6 & $18+$ & Men \\
\hline
\end{tabular}

foods such as fried chips, deep-fried doughs and sweetened beverages. Both eating healthily and avoiding unhealthy foods were concepts widely recognised by respondents as elemental in keeping mothers and children healthy.

Participants had a general understanding of the importance of diet for mothers and children and communities.

Food is a source of energy, we need food, it's nutrition ... we need to watch what we eat. We shouldn't eat just anything, because in the end it adds on things like obesity. (Man, FGD 9)

Having a baby is a lot of work, so you need to return your strength by eating healthy food. (Woman, 26-40, FGD 2)

Participants explained that food was important to promote child development and improve school performance.

Kids at school focus more on a full tummy. If they haven't eaten, kids suffer, they can't focus. (Man, FGD 9)

Similarly, it was argued that unhealthy food leads to poorer cognition in addition to increased risk of weight gain. Participants emphasised the need to limit children's consumption of unhealthy foods.

We need to pull them [children] away from eating junk ... they've put a lot of things in there, which means it makes kids obese, it makes kids to not think properly. (Woman, 26-40, FGD 1)

Participants across all ages and both genders showed some understanding of the significance of early-life nutrition, but have attributed more to the impact of a poor diet than is likely.

Food that women consume ... it affects the baby a lot when they're still in the tummy; so they need to focus on true nutritional food and try to reduce the food that is not healthy. Just consume healthy food because in the end the child will be born with all kinds of defects. (Man, FGD 9)

For your baby you need to compromise to eat ... food that has protein and vitamins ... You have to eat healthy in order to produce milk and making sure that you don't pass on funny things to the child. (Woman, 18-25, FGD 4)

Despite participants' understanding that healthy eating should be habitual, most admitted that they did not follow a healthy diet. The food they consumed daily was perceived as unhealthy and as having an adverse effect on their health and well-being.

It's the first time seeing this fat here, I mean what is that? It's this fast-food and you know there's this fat cake [deep fried doughnut] that they call ZAR $10[0.71$ USD]. We're buying food that's not right and $\ldots$ these days you can count slender kids. (Woman, 40+, FGD 8) 
Table 2 Sociodemographic characteristics of participants in focus group discussions conducted in Soweto in 2019

\begin{tabular}{|c|c|c|c|c|c|c|}
\hline \multirow[b]{2}{*}{ Population characteristics } & \multicolumn{2}{|c|}{ Men $(n 21)$} & \multicolumn{2}{|c|}{ Women ( $n$ 45) } & \multicolumn{2}{|c|}{ Total $(n 66)$} \\
\hline & $n$ & $\%$ & $n$ & $\%$ & $n$ & $\% \dagger$ \\
\hline \multicolumn{7}{|l|}{ Age (years) } \\
\hline Mean & \multicolumn{2}{|c|}{32} & \multicolumn{2}{|c|}{35} & \multicolumn{2}{|c|}{34} \\
\hline SD & \multicolumn{2}{|c|}{9} & \multicolumn{2}{|c|}{13} & \multicolumn{2}{|c|}{12} \\
\hline Minimum & \multicolumn{2}{|c|}{19} & \multicolumn{2}{|c|}{18} & \multicolumn{2}{|c|}{18} \\
\hline Maximum & \multicolumn{2}{|c|}{48} & \multicolumn{2}{|c|}{67} & \multicolumn{2}{|c|}{67} \\
\hline \multicolumn{7}{|l|}{ Number of babies and children cared for } \\
\hline 1 & 3 & 14 & 15 & 33 & 18 & 27 \\
\hline $2-4$ & 15 & 71 & 27 & 60 & 42 & 64 \\
\hline Missing data & 3 & 14 & 3 & 7 & 6 & 9 \\
\hline \multicolumn{7}{|l|}{ Marital status } \\
\hline Single, never married & 14 & 67 & 24 & 53 & 38 & 58 \\
\hline Married & 2 & 10 & 8 & 18 & 10 & 15 \\
\hline Living together & 1 & 2 & 8 & 18 & 9 & 14 \\
\hline Divorced/widowed & 3 & 14 & 4 & 9 & 7 & 11 \\
\hline Unknown & 1 & 2 & 0 & & 1 & 2 \\
\hline Missing data & 1 & 2 & 0 & & 1 & 2 \\
\hline \multicolumn{7}{|l|}{ Highest level of schooling } \\
\hline No schooling & 0 & & 1 & 2 & 1 & 2 \\
\hline Primary & 2 & 10 & 2 & 4 & 4 & 6 \\
\hline Some high & 13 & 62 & 18 & 40 & 31 & 47 \\
\hline Grade $12 /$ matric $^{*}$ & 4 & 19 & 10 & 22 & 14 & 21 \\
\hline Some tertiary education but did not graduate & 1 & 2 & 9 & 20 & 10 & 15 \\
\hline Tertiary graduate & 1 & 2 & 4 & 9 & 5 & 8 \\
\hline Missing data & 1 & 2 & 0 & & 1 & 2 \\
\hline \multicolumn{7}{|l|}{ Monthly household income (ZAR)‡ } \\
\hline$<3000$ & 14 & 67 & 29 & 64 & 43 & 65 \\
\hline $3001-5000$ & 3 & 14 & 6 & 13 & 9 & 14 \\
\hline $5000-20000$ & 2 & 10 & 3 & 7 & 5 & 8 \\
\hline$>20000$ & 1 & 2 & 3 & 7 & 4 & 6 \\
\hline Unknown & 1 & 2 & 4 & 9 & 5 & 8 \\
\hline \multicolumn{7}{|l|}{ Source of income } \\
\hline Government grants & 2 & 10 & 18 & 40 & 20 & 30 \\
\hline Employment & 4 & 19 & 6 & 13 & 10 & 15 \\
\hline Grants and employment & 1 & 2 & 9 & 20 & 10 & 15 \\
\hline Other & 14 & 67 & 6 & 13 & 20 & 30 \\
\hline No source of income & 0 & & 3 & 7 & 3 & 5 \\
\hline Missing data & 0 & & 3 & 7 & 3 & 5 \\
\hline
\end{tabular}

*Grade 12 students are between the ages of 17 and 19

†Percentages do not add up to one hundred due to rounding off.

†Households were categorised as low income if monthly household income was < ZAR 5000, middle income if ZAR $5000-25600$ and upper income if $>$ ZAR 25601.

So that thing in English is called fatty acids, fatty food; too much oil is killing us. (Man, FGD 9)

\section{Barriers to optimal nutrition in the physical}

environment

Nearly all groups indicated that their local food environment, which they felt to be unsanitary and unhygienic, and in which they described a high number of unhealthy food service outlets, is an important determinant of nutrition.

Some attributed the frequent consumption of unhealthy items to a higher density of fast-food outlets than in times gone by and to a consequent higher exposure to cheap low-quality food, sold even in schools.

Food these days is wrong, wrong, wrong. You know back then, there used to be kota [unhealthy street food]. We'd get it from school but it was scarce. But now at every corner there are those chips for R5. ([0.29 USD] Woman, 40+, FGD 8)
Community members spoke of the differences in the nature and quality of food available in local stores and how these contribute to their nutrition practices and ill health.

Our health doesn't hold only on our hands [is beyond our control] ... We must also mention that even those companies, those shops that are selling that food, others use lower grade food and that affects our health ... That shop in the corner, as small as it is, it also plays a role in our health. (Man, FGD 7)

Participants reported that they relied on harmful, highly processed foods, because healthy options such as organic vegetables and olive oil were more expensive.

Men were concerned about the poor food hygiene practices of street vendors and their ignorance of food expiry dates. 
Maybe the person that prepares that food hasn't cleaned it properly first of all, those are the things that cause some illnesses. And when something is off, you can smell it when they cook it. (Man, FGD 7)

Limited space and overcrowded households arising from rapid urbanisation of the Soweto community were thought to have caused poor environmental sanitation issues, which were key health concerns for both men and women.

The streets being filthy ... I walk out of the gate and I'm confronted by a heap of plastics. You can't even eat when you're trying to eat, you know [you lose your appetite]. That thing affects your health. (Woman, 40+, FGD 8)

For example, a small land holding where they plant whatever [vegetables for consumption], the very same waste is being thrown there and there's the sewer and stuff. And it's food that we eat! We don't know if it's healthy or not. (Man, FGD 7)

\section{Healthy diet constrained by socioeconomic hardship}

While participants perceived food to be important to keep mothers and children healthy, they could not prioritise buying healthy food. They described structural issues which both shaped their daily lives and often determined their food choices.

Lack of financial resources. Poverty and lack of income appeared to be the biggest barriers to individuals' access to optimal nutrition.

We eat it [junk food] because we can afford it, but they're not good. We don't have choice. (Woman, 26-40, FGD 1)

I'm pregnant now. I'm unemployed. How can I eat healthy food really? I can't even afford to buy food, exactly. (Woman, 40+, FGD 6)

Assuaging hunger alone came at a high cost for participants. For some, getting any food required strategies such as engaging in risky sexual behaviour or dropping out of school.

It comes from the fact that you're hungry and there's no food. Then she goes out and looks for some money somehow; so now when a guy comes along ... He starts touching her and maybe gives her about R50 [3 USD] so she can buy food. (Man, FGD 5)

The kids come back from school and there's no food. The kids are hungry and forced to go out into the streets and fend for themselves, and then that leaves no room for school. (Man, FGD 5)

Unstable bousebolds and lifestyles. There was a general perception that features of unstable households, such as single parenthood and co-habiting (not married) couples, had adverse effects on health and diet. Participants linked unhealthy infant feeding practices and nutritional deprivation in childhood to parental lifestyle, resources and relationship quality.
I'm a single parent. The kids need food, they need clothes. I need to take them to crèche [day care for babies and young toddlers]; I take them and look for someone that can stay with them, and I can't find a job. I go all over taking my CV but they don't call me back. So what do I do ... I go to town and prostitute myself so I can buy food for my kids. (Woman, 26-40, FGD 1)

Inflexible job schedules, variable work hours, working overtime and multiple jobs, lack of job security, low pay and low status jobs were all reported to make healthier choices difficult, particularly when it came to breastfeeding.

I have twins, ... I used to live with them in Soweto while attending school and I used to wake them up at $5 \mathrm{am}$. So I realised that these kids are struggling and they are losing weight even ... so it's not good for them. (Woman, 26-40, FGD 1)

I had to stop breastfeeding after a month because I had to go back to work. That's when I started introducing the bottle; but with the bottle she started being very uneasy, waking up in the middle of the night. That's when I started introducing Cerelac [instant cereal]. (Woman, 18-25, FGD 4)

Common coping strategies identified by time-pressured, low-income working mothers include consumption of takeaway food rather than home-prepared food, and shopping for convenience and snack foods. These strategies were economically efficient but often came at the cost of a healthy diet.

The kota is big and it costs about ZAR 30 [2-16 USD]. You can save by doing that instead of cooking. (Woman, 26-40, FGD 2)

Poor mental bealth. Most women associated poor parental mental health, including depression and substance abuse, with poor child nutrition and neglect. One young participant explained the way a woman's mental health might affect her diet during pregnancy.

What influences what you eat during pregnancy is your mental state. Are you bonding with the child? Do you want the child to be healthy? Some people eat bad things because they don't want the child. They don't care whether the child dies or no. They just eat whatever. (Woman, 18-25, FGD 4)

Another spoke of how women in Soweto might feel trapped by their circumstances, affecting their mental health.

It's because of the stress relating to seeing no way out of the situation that they're in [women]. Most of them don't go there saying they want to be an alcoholic, there's no woman that wants to be an alcoholic when they have kids. (Woman, 26-40, FGD 1)

Substance abuse was an important concern affecting both mothers and their children. 
Older women were particularly concerned about this and tended to link substance abuse to reproductive health problems, including teenage pregnancy, STI, HIV/AIDS and even rape.

These girls they are using drugs, they're pregnant, they don't go to the clinic. At the end of the day it's affecting that child, that unborn child. Your child will be born slow and at school as well, and then you will be in denial. (Woman, 40+, FGD 6)

Outside of home, other stressors such as bullying at school were given as additional factors that affected children's food intakes.

You're afraid to take your children to school because they bully them... Yes, you pack food for them and when they get to school they [the bullies] take their food and eat it. (Woman, 40+, FGD 8)

\section{Optimising nutrition in desperate conditions}

Participants were asked what nutritional support they already had and what else could be done to improve the nutritional status of mothers and children in their communities. Solutions revolved mostly around existing services and can be described under the following subthemes: health sector, nutrition knowledge and skills, the food system and social protection.

Health sector. Participants described clinics as the first point of contact with the health sector, and for many women, this contact was largely for antenatal care. Clinics were relied on for obtaining information on good nutritional practice; however, they were perceived as malfunctioning. Overcrowded facilities, long waiting times, unmotivated, dismissive nurses were described as contributing to participants' negative experience of services.

It's the rudeness of the clinic nurses. They are so rude that people are even afraid to go and consult because of the rudeness. (Man, FGD 7)

When you go to the clinic, people queue from around $4 \mathrm{am}$ and they're only going to get service at around $7 \mathrm{am}$ or $8 \mathrm{am}$ and they're waiting in the street. (Woman, 26-40, FGD 1)

Other existing services included rehabilitation groups for those with substance abuse; however, their lack of effectiveness was reported to be discouraging. Women across all age groups believed that they could benefit from social services such as child care to ease their burden of domestic care and work, and free up time for food preparation. Young women especially felt alone regarding child care and expressed their mistrust in institutions.

Help is very limited, ... and you go to crèche and the child is abused at crèche, the institution that's supposed to be trusted. (Woman, 18-24, FGD 4)

There was general agreement that more government health services had been available in the past through frequent home visits by health workers and home calls by nurses. Women reported that current health services are curative rather than preventative, and that they receive less information about practices on breastfeeding and less nutritional advice than in the past.

Nutrition knowledge and skills. Participants believed that current nutrition education delivered through primary care settings and the media is limited and they would benefit from improved information provision. Solutions included both nutrition counselling and knowledge translation through charts and tables with food and nutrition information.

Maybe at hospitals they need to put them at a certain place and they [women] need to be taught what to eat, what to maintain, what not to eat. (Man, FGD 7)

If there was more awareness, with advertising on TV and newspapers. There should be a section on eating healthy. I think it would go a long way. (Man, FGD 7)

Participants also suggested they needed skill building through food literacy programmes and cooking classes. These were envisioned as happening in community groups, targeted at all adults, as well as specific groups such as pregnant women and breastfeeding mothers.

If there were groups that were open ... where women know that that's where you go to learn what to eat or what not to eat. (Woman, 26-40, FGD 1)

Men also expressed willingness to improve their own knowledge, skills and behaviours.

We need to go back to knowledge. We shouldn't just eat anything, and maybe they can advise us how to eat so we can stop this. Think ... guys, we eat junk food, we eat junk food, that's why we have big bellies these days. (Man, FGD 9)

Food systems. The way to solve the problem of oversupply of unhealthy and unsafe foods was seen in better governance across the food systems and food environments. Food system refers to all elements and activities relating to growing, harvesting, processing, packaging, marketing, distributing, preparing and consuming foods ${ }^{(28)}$. Related to this are food environments that Swinburn et al. (2013) defined as the collective physical, economic, policy and sociocultural surroundings, opportunities and conditions that influence people's food and beverage choices and nutritional status ${ }^{(29)}$.

Participants envisioned increased government control of the market and policing of regulations regarding food supply and consumption, and believed that this would improve healthy eating in their communities.

I think that government must make all food equal for everyone. I think we will all be healthy. (Man, FGD 8) 
I think there's an inspectorate body that deals with shops to say 'is that food you're buying healthy'? We have that in government. Are they doing their work to check every shop, every wholesaler? Is that food you are buying as consumers healthy? Because coming back to what you say, our health is not holding in our hands only. (Man, FGD 7)

School- and home-based food gardens were considered as solutions to enhance the local food economy.

Coming back to the point on poverty, I think if we had money as people we'd be able to buy a piece of land and say here I'm going to uplift the community and plant, and people will know that veggies are available there. (Man, FGD 9)

However, significant barriers were mentioned that hindered participants' capacity to grow food. Issues of poor sanitation, lack of space, time and affordability of land were key determinants. Community members indicated the importance of addressing sanitation and hygiene issues. Services such as Pick It Up, the Soweto garbage collection service, while in place, were perceived to be ineffective.

Social protection. Participants relied on social policies that either implicitly or explicitly consider nutrition. The distribution of social grants, particularly child support grants (ZAR 420 per month per child [30 USD] as of June 2019), was perceived to be instrumental in improving access to food, and participants suggested that the grants should be increased. They also believed that coupons with conditional purchase for healthy food products or regular healthy food provisioning would improve their nutrition and health status.

I would start a feeding scheme, like when they [mothers] come back from getting their social grants; they need to come back with a little package of at least healthy food. (Man, FGD 9)

I think food parcels, the ones that have veggies specifically. (Woman, 18-25, FGD 3)

The government feeding scheme at schools and food provision at crèches was perceived to be the second most important social service. The scheme influenced the nutrition of children directly through meal provisioning, as well as indirectly by providing employment opportunities for mothers at the school. Participants saw schools as a platform to improve nutrition education of children from early age.

I think the school whereby the child goes - primary school, high school - that is also one of the services that must provide information on what they should eat. (Man, FGD 7)

While food provisioning services for children are important, they differ in quality. Some reported that 'crèches are dangerous because they sometimes give these kids food that's not good for them, and then you find the kids start throwing that food up' (Woman, 26-40, FGD 2), while others shared positive experiences of schools that monitor the healthfulness of lunch packages of children.

\section{Discussion}

To the authors' knowledge, this is the first study to generate an in-depth community perspective on maternal and child nutrition-specific matters and solutions in urban South Africa. Its value is in its ability to support 'bottomup' development of double-duty interventions to address both under and over nutrition, which are acceptable to and feasible within the community. Findings of the current study demonstrate fundamental differences in what communities perceive as important nutrition issues and solutions and what policymakers prioritise. It expands our understanding of shared determinants of under and over nutrition and suggests platforms that can be used for double-duty actions to address the various forms of malnutrition in the community.

The FGD highlighted the need to simultaneously address both the motivation and capacity of communities to optimise nutrition at individual and population levels. Participants hoped for individual-oriented opportunities to help them and their children establish healthy eating. At the community level, communal gardens and food parcels were suggested as potential solutions to lack of healthy foods such as fruit and vegetables. Participants also recognised the absence of population-wide regulatory controls over the activities of both formal and informal fast-food industries, and expressed the need for increased governmental involvement in regulating the industry.

In line with the global trend towards increased availability of heavily marketed, cheap, unhealthy food products ${ }^{(30)}$, the current study exposes the way the environment in Soweto makes it difficult for residents to eat healthily despite their desire to do so. Participants' experience of widely available and affordable unhealthy foods resonates with previous work in Gauteng Province that showed fast-food outlets and unhealthy food stores outnumber healthy food retailers in poorer communities ${ }^{(31)}$. The current study describes the excessive consumption of convenient, inexpensive and unhealthy foods by both children and adults. Previous research on dietary patterns of urban, black, pregnant South African women showed similar high intakes of fatty foods, and found these to be associated with greater gestational weight gain, higher rates of foetal growth, maternal and foetal complications and a higher risk of childhood and adolescent overweight and obesity in comparison with groups taking diets high in whole grains, legumes, vegetables and traditional meats $^{(32,33)}$. The suboptimal dietary practices of children described by men and women in this article also reflect those of the 2016 Demographic Health Survey (SADHS), 
showing that only $23 \%$ of children aged 6-23 months were fed a minimum acceptable diet, with $18 \%$ of children in the same age group consuming sugary drinks ${ }^{(5)}$.

Current nutrition services outlined in the Roadmap for Nutrition in South Africa: 2013-17, and the Infant and Young Child Feeding Policy ${ }^{(34,35)}$ are limited to short-term strategies delivered through clinics. These focus predominantly on curative nutritional services (i.e. those for patients with gestational diabetes mellitus), providing micronutrient supplements during pregnancy and supporting breastfeeding. There is less focus on addressing obesity prevention and improving maternal dietary intake and BMI prior to conception. This raises important questions about the efficiency of our current health sector with respect to nutrition. It uses scarce resources focused mostly on the treatment of malnutrition, particularly undernutrition, but does little to support individuals being sent back to living in unhealthy environments, thus failing to perform double-duty actions.

Double-duty opportunities to improve nutrition outside the health sector through crèches, schools, workplaces, churches, home and in the broader community are relatively unexplored. Some participants felt they needed more information on what they should be eating. However, knowledge was acknowledged to be only one factor in shaping maternal and child nutrition. The community's perception was that optimal nutrition (or eating healthily) had to compete with other priority issues such as lack of money, reproductive ill-health and substance abuse, poor sanitation and hygiene practices and the lack of availability of land to grow food, all of which were said to affect the nutritional status of mothers and their children ${ }^{(36,37)}$. Participants' choices were compromised because of these other aspects of their lives.

Our research indicates that there are shared environmental and socioeconomic factors that contribute to the double burden of malnutrition. Improving maternal and child nutrition in South Africa will require an integrated comprehensive approach, such as WHO's double-duty approach $^{(14)}$, with strategies addressing both intermediate and distal causes of the double burden of malnutrition. To facilitate this, the government must ensure that coherent policies are enacted at all levels - national, provincial and local - and upstream factors, including poverty, are addressed. In fact, poverty persists as one of the major barriers to prioritising health and healthy eating. Unless these upstream factors that operate at both national and international levels are addressed, the problems will continue.

\section{Transitioning out of malnutrition}

Participants' recommendations encompassed four broad areas for action, including health sector, social protection, food system and the food environment, resembling the examples of shared platforms for double-duty actions proposed by the $\mathrm{WHO}^{(14)}$. Drawing on the study findings and current South African nutrition-related policies, we propose a framework that envisions a transition towards a healthier environment enabling optimal maternal and child nutrition (Fig. 1). The majority of proposed interventions are nutrition-sensitive ${ }^{(38)}$ rather than nutrition-specific in that they minimise risk factors associated with nutritional status rather than directly addressing nutrition. These include improving household and community environments, increasing social safety nets and protecting individuals from the adverse consequences of unhealthy food environments ${ }^{(3)}$. Population-based approaches such as health information and communication campaigns, fiscal measures such as taxes on sugar-sweetened beverages, direct restrictions and mandates, reformulation and improving the nutrient profile of food products, and eliminating marketing to children can have significant and large impacts to improve diets, enhance early childhood development and reduce the incidence of $\mathrm{NCD}^{(39)}$.

The framework outlines a set of possible double-duty actions that often occur outside of the health sector, and requires the collaboration of multiple actors, including the local authority, the Department of Trade and Industry, the Department of Basic Education and the Department of Social Development. All the interventions in this framework are based on the suggestions of the participants of FGD reported in this article. The framework also indicates the need to move away from silo approaches to intervention delivery, to a focus on integrated responses where interventions reinforce the implementation and enhance the benefits of one another. For example, providing targeted food or financial assistance to support access to healthier food might not be an optimal use of limited resources if basic needs for electricity and chilled storage facilities are not met, and misperceptions and lack of skills for food preparation not addressed. Similarly, investment in nutrition education without addressing the unhealthy food environment is unlikely to result in improved diets. Therefore, a combination of interventions needs to be considered, including policy and fiscal changes, such as extending the list of food products exempted from value added tax, designed to address malnutrition in all forms and promotion of healthier diets ${ }^{(3)}$. Interventions will also require strong monitoring and evaluation to assess whether policies are successfully implemented and are having the intended effect.

Above all, any nutrition agenda should reflect health needs, economic resources and societal values of communities. Engaging the public in this agenda is, therefore, imperative. Recent innovative approaches in the field include the modification and implementation of a public engagement tool, CHAT (Choosing All Together), in a rural setting in South Africa (Tugendhaft et al. 2020(40)). Similar approaches are needed to improve current practices in priority setting for nutrition. 


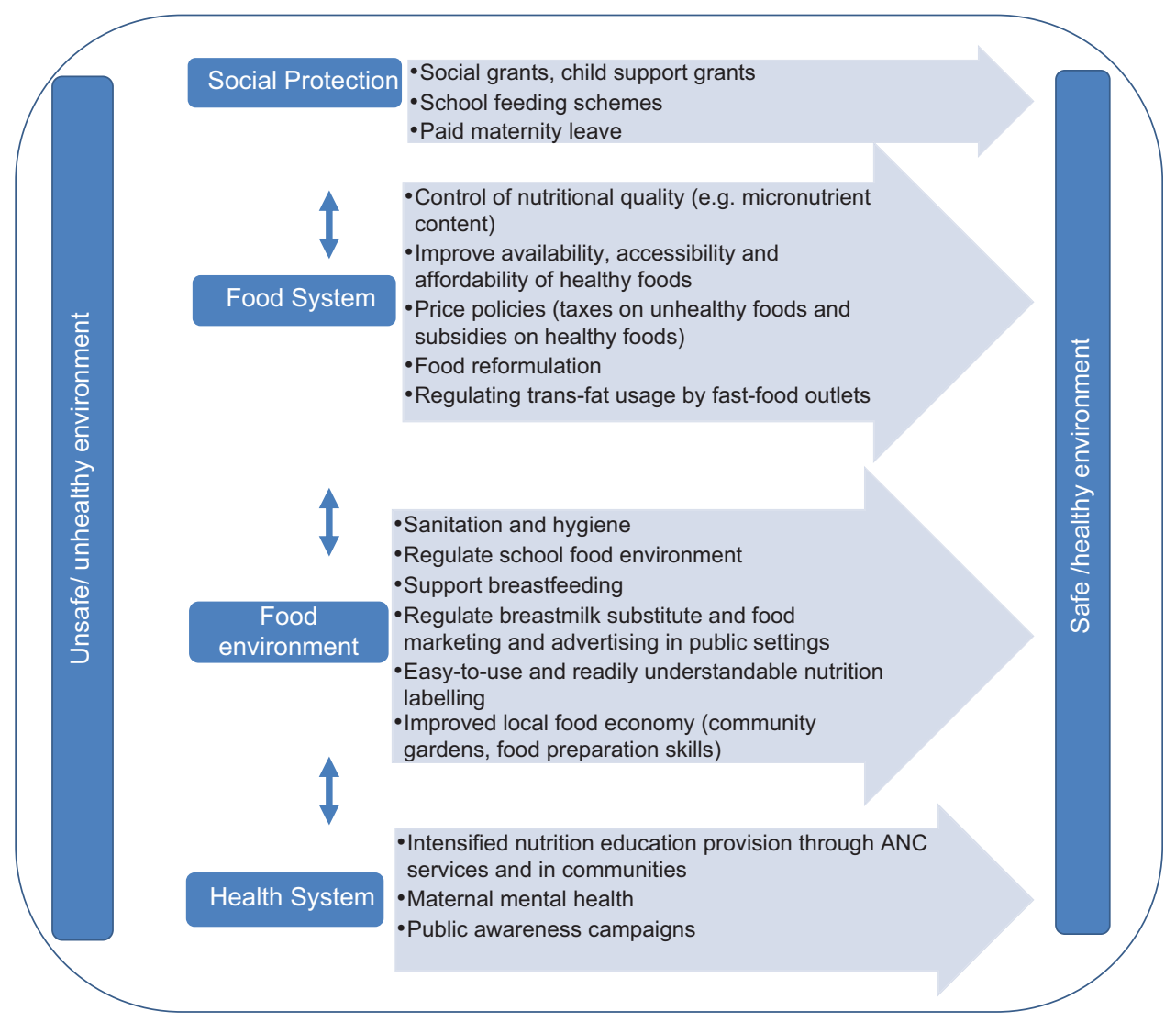

Fig. 1 (colour online) Framework to optimise nutrition for mothers and children: a summary of community solutions and supporting policies

\section{Strength and limitations}

A key strength of the current study is the involvement of researchers from diverse disciplinary backgrounds with an extensive experience in qualitative research (public health, anthropology, nutrition and psychology). Furthermore, methodological rigour, including the iterative data analysis, allowed for the incorporation of the community's voice and the avoidance of pitfalls, including taking for granted that the researcher shares the same meanings as the respondent.

Limitations of the current study include the fact that recruiting from the taxi rank meant that not all participants might have lived in Soweto as was assumed. It is possible that the perspectives of rural communities would be different to those of residents in urban Soweto. Further research would be required to understand the perceptions of rural South African communities in relation to maternal and child nutrition.

\section{Conclusion}

The double burden of malnutrition in South Africa poses a serious threat to the realisation of sustainable development because of its adverse long-term health and developmental effects. Findings reported in this article highlight the need for further public engagement and the integration of community perspectives and priorities in developing and adapting nutrition policies and practices. In the interim, and at a minimum, the government - both local and national - must play a bigger role in supporting healthy and nutritious choices by creating incentives, and disincentives, for purchasing specific foods; introducing easy frontof-pack labelling; limitations or standards on sugar, trans fats and salt content in processed foods; as well as setting standards for marketing, such as limiting advertising of unhealthy foods and beverages to children.

Even if these were in place, South Africa's current nutrition policies do not adequately address community-level needs that are often linked to structural factors beyond the health sector. Efforts to address unemployment, social inequities, hygiene and sanitation, violence and crime will be key with anticipated knock-on effects for health outcomes, including sustained reductions in the rates of malnutrition across the life cycle. Harmonisation of policies and programmes across sectors is critical to strengthen the resilience of communities and to support them in attaining optimal nutrition for mothers and their children. 


\section{Acknowledgements}

Acknowledgements: The authors would like to acknowledge Thulile Shongwe and Siyolo Mkatshwa who facilitated the FGD, and the members of the community who participated in the current study. Financial support: This research was funded by the National Institute for Health Research (NIHR) (17\63\154) using aid from the UK government to support global health research. The views expressed in this publication are those of the authors and not necessarily those of the NIHR or the UK Department of Health and Social Care. K.J.H., S.G. and A.E. are supported by South African Medical Research Council/Centre for Health Economics and Decision Science - PRICELESS SA, University of the Witwatersrand School of Public Health, Faculty of Health Sciences, Johannesburg South Africa (D1305910-03). S.A.N. is supported by the DST-NRF Centre of Excellence in Human Development at the University of the Witwatersrand, Johannesburg, and the South African Medical Research Council. S.A.N. is further supported by the NIHR through the NIHR Southampton Biomedical Research Centre, at the University of Southampton. Conflict of interest: None. Authorship: A.E., S.A.N., M.B., E.C., K.J.H. designed the study, A.E. and S.G. carried it out, A.E., S.G., D.W., M.B. analysed the data. All authors contributed to drafting and editing the article and approved the final manuscript. Ethics of human subject participation: The current study was conducted according to the guidelines laid down in the Declaration of Helsinki, and all procedures involving research study participants were approved by the University of the Witwatersrand Human Research Ethics Committee (Medical) (clearance certificate number M181056) and the University of Southampton (47 290). Written informed consent was obtained from all subjects.

\section{References}

1. Vorster H (2010) The link between poverty and malnutrition: a South African perspective. Health SA Gesondheid 15, 6 .

2. Bourne LT, Lambert EV \& Steyn K (2002) Where does the black population of South Africa stand on the nutrition transition? Public Health Nutr 5, 157-162.

3. Hawkes C, Ruel MT, Salm L et al. (2020) Double-duty actions: seizing programme and policy opportunities to address malnutrition in all its forms. Lancet 395, 142-155.

4. Mamabolo RL, Alberts M, Steyn NP et al. (2005) Prevalence and determinants of stunting and overweight in 3-year-old black South African children residing in the Central region of Limpopo province, South Africa. Public Health Nutr 8, 501-508.

5. Statistics South Africa (2017) South Africa Demographic and Health Survey 2016. Pretoria: Statistics South Africa. http:// www.mrc.ac.za/bod/SADHS2016.pdf (accessed November 2019).

6. Kimani-Murage EW (2013) Exploring the paradox: double burden of malnutrition in rural South Africa. Global Health Action 6, 19249.
7. Maimela E, Alberts M, Modjadji SEP et al. (2016) The prevalence and determinants of chronic non-communicable disease risk factors amongst adults in the Dikgale health demographic and surveillance system (HDSS) site, Limpopo province of South Africa. PLOS ONE 11, e0147926.

8. Afshin A, Sur PJ, Fay KA et al. (2019) Health effects of dietary risks in 195 countries, 1990-2017: a systematic analysis for the global burden of disease study 2017. Lancet 393, 1958-1972.

9. Victora CG, Adair L, Fall C et al. (2008) Maternal and child undernutrition: consequences for adult health and human capital. Lancet 371, 340-357.

10. Godfrey KM, Gluckman PD \& Hanson MA (2010) Developmental origins of metabolic disease: life course and intergenerational perspectives. Trends Endocrinol Metab 21, 199-205.

11. National Department of Health (2013) Strategic Plan for the Prevention and Control of Non-Communicable Diseases 2013-17. Pretoria: National Department of Health. http://www.hsrc.ac.za/uploads/pageContent/3893/NCDs \%20STRAT\%20PLAN\%20 \%20CONTENT\%208\%20april\% 20proof.pdf (accessed October 2019).

12. National Planning Commission (2012) Our Future - Make it Work: National Development Plan 2030. Cape Town: Department of The Presidency, South Africa. https://www. gov.za/sites/default/files/NDP-2030-Our-future-make-itwork_r.pdf (accessed October 2019).

13. United Nations (2015) Transforming Our World: The 2030 Agenda for Sustainable Development. United Nation. http://www.un.org/ga/search/view_doc.asp?symbol=A/RES/ 70/1\&Lang=E (accessed October 2019).

14. World Health Organization (2017) The Double Burden of Malnutrition: Policy Brief. Geneva: World Health Organization. Report No.: WHO/NMH/NHD/17.3. https://apps.who. int/iris/bitstream/handle/10665/255413/WHO-NMH-NHD17.3-eng.pdf?ua=1 (accessed May 2019).

15. Compaoré A, Ouedraogo K, Boua R et al. (2020) 'Men are no more playing their roles', maternal and child nutrition in Nanoro, Burkina Faso. Public Health Nutr.

16. Debpuur C, Nonterah EA, Chatio ST et al. (2020) Supporting maternal and child nutrition: views from community members in rural Northern Ghana. Public Health Nutr.

17. Watson D, Kehoe, SH, Erzse A et al. (2020) Community perspectives of maternal and child health during nutrition and economic transition in sub-Saharan Africa. Public Health Nutr.

18. Nyati LH, Pettifor JM \& Norris SA (2019) The prevalence of malnutrition and growth percentiles for urban South African children. BMC Public Health 19, 492.

19. Ware LJ, Prioreschi A, Bosire E et al. (2019) Environmental, social, and structural constraints for health behavior: perceptions of young Urban black women during the preconception period: a healthy life trajectories initiative. J Nutr Educ Behav 51, 946-957.

20. Macaulay S, Ngobeni M, Dunger DB et al. (2018) The prevalence of gestational diabetes mellitus amongst black South African women is a public health concern. Diabetes Res Clin Pract 139, 278-287.

21. Prioreschi A, Wrottesley S, Draper CE et al. (2017) Maternal and early life nutrition and physical activity: setting the research and intervention agenda for addressing the double burden of malnutrition in South African children. Glob Health Action 10, 1301085.

22. Krueger RA \& Casey MA (2000) Focus Groups: A Practical Guide for Applied Research. Thousand Oaks, California: SAGE Publications.

23. Baragwanath Transport Interchange and Traders Market, Johannesburg (2019) Ludwig Hansen Architects Urban designers. http://www.ludwighansen.co.za (accessed June 2019). 
24. QSR International (2020) NVivo Qualitative Data Analysis Software. https://www.qsrinternational.com/nvivo/home (accessed January 2020).

25. Virginia B, Victoria C \& Nikki H (2018) Thematic analysis. In Handbook of Research Methods in Health Social Sciences [P Liamputtong, editor]. Singapore: Springer.

26. Tong A, Sainsbury P \& Craig J (2007) Consolidated criteria for reporting qualitative research (COREQ): a 32-item checklist for interviews and focus groups. Int J Qual Health Care 19, 349-357.

27. Greyling L \& Mears R (2014) Demographic characteristics of Soweto: a comparison of 1993 and 2008. JEIEFB 3, 20.

28. United Nations System Standing Committee On Nutrition (2016) Investments for Healthy Food Systems, Implementing the Framework for Action of the Second International Conference on Nutrition, Executive Summary. https://www. unscn.org/files/ICN2_TPM/EN_final_Investments_for_ Healthy_Food_Systems_UNSCN.pdf (accessed March 2020).

29. Swinburn B, Sacks G, Vandevijvere S et al. (2013) INFORMAS (International Network for Food and Obesity/noncommunicable diseases Research, Monitoring and Action Support): overview and key principles. Obes Rev 1, 1-12.

30. Popkin BM, Adair LS \& Ng SW (2012) Global nutrition transition and the pandemic of obesity in developing countries. Nutr Rev 70, 3-21.

31. Ndlovu N, Sartorius B, Hofman K et al. (2018) Assessment of food environments in obesity reduction: a tool for public health action. In South African Health Review 2018 Durban: Health Systems Trust. http://www.hst.org.za/ publications/Pages/SAHR2018 (accessed July 2019).

32. Wrottesley SV, Pisa PT \& Norris SA (2017) The influence of maternal dietary patterns on body mass index and gestational weight gain in Urban black South African women. Nutrients 9, 732 .
33. Wrottesley SV, Prioreschi A, Kehoe SH et al. (2019) A maternal 'mixed, high sugar' dietary pattern is associated with fetal growth. Maternal Child Nutr. doi: 10.1111/mcn.12912.

34. National Department of Health (2013) Roadmap for Nutrition in South Africa 2013-2017. Pretoria, South Africa: National Department of Health. http://www.adsa.org.za/Portals/14/ Documents/DOH/Nutrition\%20Road\%20Map\%202013-2017. pdf (accessed July 2019).

35. National Department of Health (2013) South Africa Infant and Young Child Feeding Policy. Pretoria, South Africa: National Department of Health. https://www.health-e.org. za/wp-content/uploads/2013/09/IYCF_Policy_2013.pdf (accessed July 2019).

36. Richter LM, Mathews S \& Kagura J (2018) A longitudinal perspective on violence in the lives of South African children from the Birth to Twenty Plus cohort study in Johannesburg-Soweto. South Afr Med J 108, 181-186.

37. Ramsoomar L, Morojele NK \& Norris SA (2013) Alcohol use in early and late adolescence among the Birth to Twenty cohort in Soweto, South Africa. Glob Health Action 6, 57-66. doi: 10.3402/gha.v6i0.19274

38. Ruel MT \& Alderman H (2013) Nutrition-sensitive interventions and programmes: how can they help to accelerate progress in improving maternal and child nutrition? Lancet 382, 536-551.

39. World Health Organization (2012) Population-Based Approaches to Childhood Obesity: Prevention. Geneva, Switzerland: World Health Organization. https://apps.who. int/iris/bitstream/handle/10665/80149/9789241504782_eng. pdf?sequence $=1$ (accessed January 2020).

40. Tugendhaft A, Danis M, Christofides N et al. (2020) CHAT SA: modification of a public engagement tool for priority setting for a South African Rural Context. Int J Health Policy x, 1-13. doi: 10.34172/IJHPM.2020.110. 